ORIGINAL ARTICLE

\title{
Comparison of urban and rural non-fatal injury: the results of a statewide survey
}

\author{
M Leff, L Stallones, T J Keefe, R Rosenblatt, M Reeds
}

Injury Prevention 2003;9:332-337

See end of article for authors' affiliations ....................

Correspondence to: Marilyn Leff, Colorado Injury Control Research Center, Colorado State University, Ft Collins, $\mathrm{CO}$ 80523-1676, USA marilyn.leff@colostate.edu

\begin{abstract}
Objectives: This study compared the epidemiology of non-fatal injury among urban and rural residents of Colorado.

Design: A stratified probability sample with random digit dial methods was used to survey Colorado residents by telephone regarding injuries experienced in the last 12 months. Questions on the cause of the injury, the activity at the time of the injury, and the place of injury were based on the Nordic Medico Statistical Committee's (NOMESCO) classification of external causes of injuries.

Subjects: A total of 1425 urban and 1275 rural Colorado residents aged 18 and older were interviewed. Results: Age, gender, marital status, and rural residency were found to increase the odds of self reported injury. The adjusted odds ratio for self reported injury was 1.3 (95\% confidence interval (CI) 1.01 to 1.68) for rural compared with urban residents. Rural residence (odds ratio $1.02,95 \% \mathrm{Cl} 0.51$ to 7.01 ) was not a risk factor for injury among the highest risk group, those who were single and never married. No differences in injury characteristics were found by urban-rural status.

Conclusions: The increased odds of self reported injury among rural residents were not explained by differences in the causes of injury or other injury characteristics. The differences in the importance of rural residence in increased odds of injury by marital status warrants further understanding and may be important in the development of injury prevention programs. Based on comparison with a similar survey, the NOMESCO coding system appears to be a viable alternative survey tool for gathering information on injury characteristics.
\end{abstract}

\section{METHODS}

\section{Survey methods}

A population based survey of non-institutionalized Colorado adults was conducted beginning January 1999 through October 2000. The survey design and sampling methods used followed those of the Behavioral Risk Factor Surveillance System (BRFSS). ${ }^{8}$ The sample consisted of two strata: urban and rural. Counties with a metropolitan area of more than 100000 people or a city with a population of at least 50000 people were classified as urban. All other counties were classified as rural. Telephone calls were made to the urban areas from January1999 through December 1999 and to the rural areas from January 1999 through September 2000. Random digit dial telephone techniques were used to identify households within each stratum. One adult, 18 and older, was randomly chosen from each household to participate in

the survey. Calling and quality control procedures followed those of the BRFSS. ${ }^{8}$

\section{Questionnaire design}

The main purpose of the survey was to describe disability in the state. A series of questions about injury were added which asked respondents if they had an injury in the last 12 months that required medical attention other than first aid and/or that caused restriction of usual activities for a day or more. For all those who responded positively detailed questions were asked about the most recent injury including:

1. If the injury occurred on a farm or ranch.

2. The number of missed days of work/regular activity due to the injury.

3. If the respondent was the driver or passenger of a motorized vehicle when the injury occurred.

4. The activity at the time of injury.

5. The place the injury occurred.

6. The events that caused the injury.

7. If the injury was intentional or unintentional.

Characteristics 4 through 6 were coded using the Nordic Medico Statistical Committee's (NOMESCO) classification of external causes of injuries. ${ }^{90}$ This classification scheme has two levels of coding with one digit coding designed "to enable staff without special training" to use the codes (NOMESCO Working Group, p14). ${ }^{9}$

Abbreviations: BRFSS, Behavioral Risk Factor Surveillance System; NOMESCO, Nordic Medico-Statistical Committee; CMSA, consolidated metropolitan statistical area; MSA, metropolitan statistical area; $\mathrm{Cl}$, confidence interval 
Demographic questions were taken from the 1999 BRFSS. ${ }^{11}$ An index of poverty level was determined using the United States Department of Health and Human Services 2000 poverty guidelines. ${ }^{12}$ Respondents were categorized as living in households near or below poverty or above poverty guidelines. Poverty level is dependent on the number of household residents and the household income. Since the income categories on the BRFSS questionnaire were not the same as those found on the poverty guidelines, some respondents could not be classified as below or above poverty level. They instead could have been classified as either right below or right above these two poverty levels. These respondents were assigned as near the poverty level.

\section{Data analysis}

A weight, accounting for probability of selection and nonresponse bias, was developed for each respondent according to guidelines developed for weighting BRFSS survey data. ${ }^{13}$ The data were analyzed using SAS, version 8.1 together with IVEware to account for the weighting procedure and the complex survey design. ${ }^{14}{ }^{15}$ Proportions and 95\% confidence intervals were developed separately for urban and rural residents as well as the statewide population.

Design based logistic regression modeling techniques were used to identify those demographic characteristics associated with reporting at least one injury in the last 12 months. ${ }^{16}$ It was decided a priori to keep all those variables with a $\mathrm{p}$ value of less than 0.15 in the multiple logistic regression model. All variables, including those not found to be statistically significant, were tested as potential confounders. Confounding was defined as a variable whose addition to the model changed the odds ratio of one of the other variables by $10 \%$ or more. Main effects included in the final multiple logistic regression model were those variables which continued to have a statistically significant coefficient at $p<0.15$ and/or were found to confound the effects of those variables. First order interaction terms in which the Wald test for significance of the coefficient was less than 0.05 were considered to be significant interactions.

We repeated the logistic regression analysis to investigate if the odds of reporting an injury differed by type of urban and rural county. Urban and rural counties were further subdivided into four mutually exclusive regions: Denver Metro consolidated metropolitan statistical area (CMSA), other metropolitan statistical areas (MSAs), rural nonremote, and rural remote. The rural non-remote category consisted of counties that either: (1) had a population center greater than 2500 or (2) were adjacent to either the Denver Metro CMSA or the other MSA counties. Rural remote counties included those that had a population center less than 2500 and were not adjacent to an urban county.

\section{RESULTS}

A total of 4306 Colorado households were contacted for the study: 2380 urban and 1926 rural. A total of 2713 individuals agreed to participate; 13 respondents with missing data necessary for weighting were excluded. Following the methods used by the BRFSS in calculating response rates, the response rate in the urban stratum was $57.4 \%$ compared with $63.4 \%$ in the rural stratum. ${ }^{17}$

\section{Descriptive results}

Table 1 provides the weighted estimates of the distribution of demographic variables for the total sample and for the urban and rural counties. The demographic characteristics were similar except that rural residents were less likely to have attended college than urban residents. While not statistically significant, rural residents were also more likely to be older and less likely to have incomes above the poverty level.
Statewide, $14.7 \%$ of adults reported having had at least one injury in the last 12 months (table 2). Those 18-24 years and never married individuals had the highest proportions of self reported injuries. The two oldest age groups had the lowest proportion of those reporting an injury. Over $17 \%$ of rural residents reported having an injury compared with over $14 \%$ among urban residents. In most subgroups rural residents more often reported being injured than urban residents. When breaking county type down further, rural remote residents had the highest proportion reporting injuries (22.6\%, 95\% confidence interval (CI) 15.0 to 30.1), followed by rural non-remote residents (16.6\%, $95 \%$ CI 13.9 to 19.4 ). Urban residents outside the Denver Metro region had the lowest proportion $(12.1 \%$, 95\% CI 8.7 to 15.4 ) with $14.9 \%$ (95\% CI 12.2 to 17.6) of Denver Metro residents experiencing an injury in the last 12 months.

Table 3 summarizes the injury characteristics of the most recent injury by urban and rural status. The characteristics of the injuries to rural respondents were similar to those of urban respondents. A third of all injuries in both rural and urban areas took place in the home. More than $10 \%$ of rural respondents reported that the injury took place on a farm or ranch compared with $4 \%$ of urban respondents. Of all of the injuries on a farm/ranch, a third of them took place in a home (data not shown).

Causes of injury did not differ when comparing urban and rural residents (table 3 ). The most common causes of injury were overexertion and being struck or hit from a fall. These injuries accounted for greater than $50 \%$ of all injuries among rural and urban residents. Twelve percent of the injuries occurred while the respondent was a driver or passenger in a motor vehicle for urban and rural residents (table 3).

Working for income was the most frequently reported activity at the time of injury for both rural and urban residents. Rural respondents were less likely to report doing unpaid work at the time of injury compared with their urban counterparts; urban respondents were also more likely to report being involved in sporting activities at the time of injury compared with rural residents (table 3).

Thirty one percent of injuries to rural residents kept the individuals from their usual activities for six or more days while $28 \%$ of the injuries to urban residents required this restriction (table 3 ). Only five of the injuries were reported as intentional: four assaults and one suicide attempt (data not shown).

\section{Multivariate results}

Four variables were associated with self reported injury: residence, marital status, age group, and gender (table 4). After adjustment for age, gender, and marital status, the odds of rural residents incurring at least one non-fatal injury in the last 12 months were 30\% higher compared with their urban counterparts. Residents of rural remote areas were over $60 \%$ more likely to incur a non-fatal injury compared with the residents of the Denver CMSA (odds ratio 1.64, 95\% CI 0.99 to 2.73 ).

Based on the evaluation of interaction terms, marital status was found to have a differential effect on the other three variables. There were no respondents age 65 and older who had had an injury in the last year and who also were never married. Since the 55-64 year old age group showed no difference in odds of injury compared to the 65 and older group (table 5), the two oldest age groups were combined into one for the interaction analysis. Within the never married group, the youngest ages and males had the highest odds of self reported injury (table 5). Rural residents in this group had no higher risk than their urban counterparts. Among the formerly married respondents, those in the rural areas were over $80 \%$ more likely to report an injury than their 


\begin{tabular}{|c|c|c|c|}
\hline & Urban $(n=1425)$ & Rural $(n=1275)$ & Statewide $(n=2700)$ \\
\hline \multicolumn{4}{|l|}{ Gender } \\
\hline Male & $49.6(46.6$ to 52.5$)$ & $52.4(49.1$ to 55.6$)$ & $50.0(47.5$ to 52.5$)$ \\
\hline Female & 50.4 (47.5 to 53.3$)$ & $47.6(44.3$ to 50.9$)$ & $50.0(47.5$ to 52.5$)$ \\
\hline \multicolumn{4}{|l|}{ Age group } \\
\hline $18-24$ & $13.7(11.2$ to 16.1$)$ & $12.1(9.4$ to 14.8$)$ & $13.4(11.3$ to 15.5$)$ \\
\hline $25-34$ & 21.1 (18.8 to 23.4$)$ & $18.2(15.6$ to 20.7$)$ & $20.6(18.7$ to 22.6$)$ \\
\hline $35-44$ & 23.1 (20.6 to 25.5$)$ & $22.4(19.8$ to 25.0$)$ & $23.0(20.9$ to 25.1$)$ \\
\hline $45-54$ & 19.1 (16.9 to 21.3$)$ & $20.4(17.7$ to 23.0$)$ & $19.3(17.4$ to 21.2$)$ \\
\hline $55-64$ & $10.3(8.6$ to 12.1$)$ & $12.0(10.0$ to 14.1$)$ & $10.6(9.1$ to 12.1$)$ \\
\hline \multirow{2}{*}{\multicolumn{4}{|c|}{ Ethnicity }} \\
\hline & & & \\
\hline Hispanic & $16.7(14.5-19.0)$ & 14.8 (12.2 to 17.4$)$ & $16.4(14.5$ to 18.4$)$ \\
\hline Non-Hispanic & 83.3 (81.0 to 85.5 & $85.2(82.6$ to 87.8$)$ & $83.6(81.6$ to 85.5$)$ \\
\hline \multicolumn{4}{|l|}{ Poverty status } \\
\hline Near or below poverty & $8.8(7.0$ to 10.7$)$ & $12.2(9.9$, to 14.4$)$ & $9.4(7.8$, to 11.0$)$ \\
\hline Above poverty & $91.2(89.3$ to 93.1$)$ & $87.8(85.5$ to 90.1$)$ & 90.6 (89.8 to 92.2 ) \\
\hline \multicolumn{4}{|l|}{ Education } \\
\hline Less than high school & $9.6(7.8$ to 11.3$)$ & $10.3(8.4$ to 12.3$)$ & $9.7(8.1$ to 11.2$)$ \\
\hline High school graduate & $29.3(26.6$ to 32.0$)$ & 35.2 (32.0 to 38.3 ) & $30.3(27.9$ to 32.6$)$ \\
\hline Some college & 61.1 (58.3 to 64.0 ) & 54.5 (51.2 to 57.8$)$ & 60.1 (57.6 to 62.5$)$ \\
\hline \multicolumn{4}{|l|}{ Marital status } \\
\hline Married/unmarried couple & $64.1(61.2$ to 66.9$)$ & 67.1 (64.0 to 70.2$)$ & $64.6(62.2$ to 67.0$)$ \\
\hline Divorced/separated/widowed & $17.6(15.6$ to 19.5$)$ & $17.4(15.2,19.5)$ & 17.6 (15.9 to 19.2$)$ \\
\hline Single, never married & $18.3(14.8$ to 21.9$)$ & 15.5 (12.8 to 18.2$)$ & $17.9(15.8$ to 20.0$)$ \\
\hline
\end{tabular}

urban counterparts. Married, rural residents showed close to a $30 \%$ increase in the odds of self reported injury compared with their married, urban counterparts but this increased odds was no longer statistically significant in the interaction analysis. Only young age (18-24) was a statistically significant risk factor for injury among the married group.

\section{DISCUSSION}

The odds of self reported injury were 30\% higher for rural residents compared with urban residents when adjusted for age, gender, and marital status. Residents of rural remote counties had the highest odds of injury. The increase in self reported injury among rural residents is comparable to the difference in age adjusted death rates for urban and rural counties. (30\% $v 21 \%$ ) (personal communication, Injury Epidemiology Program, Colorado Department of Public Health and Environment). In this study, no major differences were noted for urban and rural residents in the place, cause, or activity at the time of injury. Considering all of the above, this finding would suggest that non-fatal injuries are not different in rural and urban areas, rather that given comparable populations in age, gender, and marital status, injuries would occur more often in rural than urban areas. We found that other groups at higher risk of injury mortality and hospitalization were not at high risk of self reported injuries. As an example, in Colorado $31 \%$ of all injury deaths

\begin{tabular}{|c|c|c|c|}
\hline & Urban $(n=1425)$ & Rural $(n=1275)$ & Statewide $(n=2700)$ \\
\hline \multirow{2}{*}{\multicolumn{4}{|c|}{ Gender }} \\
\hline & & & \\
\hline Male & 16.2 (12.7 to 19.7$)$ & 20.1 (16.0 to 24.3 ) & 16.8 (13.9 to 19.8$)$ \\
\hline Female & $12.2(9.8$ to 14.7$)$ & $14.4(11.5$ to 17.4$)$ & 12.6 (10.4 to 14.7$)$ \\
\hline \multicolumn{4}{|l|}{ Age group } \\
\hline $18-24$ & $23.4(14.6$ to 32.1$)$ & 25.6 (14.3 to 36.8 ) & $23.7(16.0$ to 31.4$)$ \\
\hline $25-34$ & $12.8(8.7$ to 16.8$)$ & $18.2(12.1$ to 24.3$)$ & $13.6(10.0$ to 17.1$)$ \\
\hline $35-44$ & $14.3(10.1$ to 18.5$)$ & $19.0(13.9$ to 24.1$)$ & 15.0 (11.4 to 18.7$)$ \\
\hline $45-54$ & $13.1(8.6$ to 17.5$)$ & 15.5 (10.4 to 20.6$)$ & $13.5(9.7$ to 17.3$)$ \\
\hline $55-64$ & $9.4(4.6$ to 14.2$)$ & $19.9(12.8$ to 26.9$)$ & $11.3(7.2$ to 15.5$)$ \\
\hline \multirow{2}{*}{\multicolumn{4}{|c|}{ Ethnicity }} \\
\hline & & & \\
\hline Hispanic & $14.2(8.9$ to 19.5$)$ & $17.6(9.2$ to 26.0$)$ & 14.7 (10.0 to 19.3$)$ \\
\hline Non-Hispanic & 14.1 (11.8 to 19.5$)$ & $17.3(14.6$ to 20.0$)$ & $14.7(12.6$ to 16.7$)$ \\
\hline \multicolumn{4}{|l|}{ Poverty status } \\
\hline Near or below poverty & $12.0(5.1$ to 18.8$)$ & $16.6(9.6$ to 23.6$)$ & $12.9(7.3$ to 18.4$)$ \\
\hline Above poverty & $14.6(12.2$ to 17.0$)$ & 16.8 (14.0 to 19.6$)$ & 15.0 (12.9 to 17.1$)$ \\
\hline \multicolumn{4}{|l|}{ Education } \\
\hline Less than high school & $10.7(4.1$ to 17.4$)$ & $17.5(9.5$ to 25.5$)$ & $11.9(6.3$ to 17.6$)$ \\
\hline High school graduate & $14.2(10.4$ to 18.0$)$ & $15.3(10.8$ to 19.8$)$ & $14.4(11.2$ to 17.6$)$ \\
\hline Some college & 14.7 (11.9 to 17.6$)$ & 18.8 (15.3 to 22.2 ) & 15.3 (12.9 to 17.8$)$ \\
\hline \multicolumn{4}{|l|}{ Marital status } \\
\hline Married/unmarried couple & 12.9 (10.4 to 15.3$)$ & 15.9 (12.9 to 18.9$)$ & 13.4 (11.3 to 15.5$)$ \\
\hline Divorced/separated/widowed & $10.6(7.1$ to 14.2$)$ & 17.7 (12.8 to 22.6$)$ & $11.8(8.7$ to 14.8$)$ \\
\hline Single, never married & 22.3 (15.3 to 29.2$)$ & 23.7 (14.8 to 32.5$)$ & 22.5 (16.3 to 28.6$)$ \\
\hline
\end{tabular}




\begin{tabular}{|c|c|c|c|}
\hline & Urban $(n=191)$ & Rural $(n=207)$ & Statewide $(n=398)$ \\
\hline \multicolumn{4}{|l|}{ Place injury occurred } \\
\hline Home & 33.1 (25.5 to 40.7$)$ & 33.2 (25.7 to 40.6$)$ & 33.1 (26.8 to 39.4$)$ \\
\hline Sports area & $16.4(9.1$ to 23.8$)$ & $9.5(4.7$ to 14.3$)$ & $15.0(9.0$ to 21.1$)$ \\
\hline Transportation area & $14.8(9.1$ to 20.5$)$ & 15.5 (8.2 to 22.7 ) & $14.9(10.1$ to 19.7$)$ \\
\hline Production/workshop area & $13.9(8.2$ to 19.6$)$ & 20.4 (13.7 to 27.1$)$ & $15.2(10.4$ to 20.0$)$ \\
\hline Open areas in nature & $5.5(2.1$ to 8.9$)$ & $9.1(4.4$ to 13.9$)$ & $6.2(3.3$ to 9.1$)$ \\
\hline Other & $16.3(10.3$ to 22.2$)$ & $12.4(7.5$ to 17.2$)$ & $15.5(5.6$ to 25.4$)$ \\
\hline Injured on farm/ranch & $4.0(0.9$ to 7.1$)$ & $10.7(6.1$ to 15.3$)$ & $5.3(2.7$ to 8.0$)$ \\
\hline \multicolumn{4}{|l|}{ Cause of injury } \\
\hline Acute overexertion & 31.1 (23.0 to 39.3$)$ & 27.1 (20.0 to 34.2 ) & $30.4(23.7$ to 37.0$)$ \\
\hline Struck/hit from fall & $24.7(17.9$ to 31.6$)$ & 28.0 (20.7 to 35.3 ) & $25.4(19.7$ to 31.1$)$ \\
\hline Struck/hit from collision & $13.9(8.4$ to 19.4$)$ & 18.5 (10.9 to 26.0$)$ & 14.8 (10.1 to 19.5$)$ \\
\hline Crushing, cutting, piercing & 11.6 (5.9 to 17.2 ) & $14.1(8.4$ to 19.8$)$ & $12.1(7.4$ to 16.7$)$ \\
\hline Other & 18.6 (6.8 to 30.5$)$ & $12.3(0.9$ to 23.7$)$ & $17.4(7.6$ to 27.2$)$ \\
\hline Injured while in a motor vehicle & 12.1 (6.8 to 17.3$)$ & $12.8(5.9$ to 19.7$)$ & $12.2(7.8$ to 16.6$)$ \\
\hline \multicolumn{4}{|l|}{ Activity at the time of injury } \\
\hline Working for income & $31.7(23.7$ to 39.6$)$ & 34.1 (26.4 to 41.8 ) & 32.2 (25.6 to 38.7$)$ \\
\hline Unpaid work & $29.2(21.9$ to 36.4$)$ & $18.9(13.0$ to 24.8$)$ & 27.1 (21.2 to 33.0$)$ \\
\hline Sports, athletics, exercise & $23.2(15.4$ to 31.0$)$ & $19.0(12.5$ to 25.5$)$ & 22.4 (16.0 to 28.8$)$ \\
\hline Other & $16.0(4.4$ to 27.6$)$ & 28.0 (16.7 to 39.2 ) & $18.4(8.9$ to 27.9$)$ \\
\hline \multicolumn{4}{|c|}{ Number of missed days of work or regular activity } \\
\hline None & $35.4(27.0$ to 43.8$)$ & 39.1 (31.0 to 47.2 ) & $36.1(29.2$ to 43.0$)$ \\
\hline $1-5$ & $36.2(28.2$ to 44.2$)$ & $29.9(22.5$ to 37.3$)$ & $35.0(28.4$ to 41.5$)$ \\
\hline$\geqslant 6$ & $28.4(17.9$ to 38.9$)$ & $31.0(20.5$ to 41.6$)$ & $28.9(20.3$ to 37.6$)$ \\
\hline
\end{tabular}

were to those 55 and older a group that comprises approximately $18 \%$ of the population. ${ }^{18}{ }^{19}$ In this study, those 55 and older had the lowest odds of self reported injury of any age group. Whereas, Hispanics have significantly higher injury death rates in Colorado than do white non-Hispanics, we did not see that differential in self reported injury. ${ }^{18}$ This suggests that the epidemiology of non-fatal injuries is not entirely similar to that of fatal injuries.

\section{Marital status and injury}

We found marital status to be an important variable in understanding urban and rural differences in self reported

Table 4 Crude and adjusted odds ratios* $195 \%$ confidence interval) for self reported injury: Colorado, 1999-2000

\begin{tabular}{|c|c|c|}
\hline & Crude odds ratio & Adjusted odds ratios* \\
\hline \multicolumn{3}{|l|}{ County type } \\
\hline Rural & $1.28(0.99$ to 1.65$)$ & $1.30(1.01 \text { to } 1.68)^{* *}$ \\
\hline Urban & Referent & Referent \\
\hline \multicolumn{3}{|l|}{ Alternative county type } \\
\hline Rural remote & $1.66(1.16 \text { to } 2.70)^{* *}$ & 1.64 (0.99 to 2.73 ) \\
\hline Rural non-remote & $1.14(0.85$ to 1.52$)$ & $1.18(0.88$ to 1.58$)$ \\
\hline Non-Denver Metro & $0.78(0.53$ to 1.15$)$ & $0.81(0.55$ to 1.19$)$ \\
\hline Denver Metro & Referent & Referent \\
\hline \multicolumn{3}{|l|}{ Gender } \\
\hline Male & $1.41(1.06 \text { to } 1.88)^{* *}$ & $1.34(1.00 \text { to } 1.79)^{* *}$ \\
\hline Female & Referent & Referent \\
\hline \multicolumn{3}{|l|}{ Age group } \\
\hline $18-24$ & $2.47(1.35 \text { to } 4.51)^{* * *}$ & ${ }^{*} 1.81(0.95$ to 3.46$)$ \\
\hline $25-34$ & $1.25(0.74$ to 2.10$)$ & $1.10(0.65$ to 1.87$)$ \\
\hline $35-44$ & $1.41(0.85$ to 2.34$)$ & $1.31(0.80$ to 2.19$)$ \\
\hline $45-54$ & $1.24(0.73$ to 2.11$)$ & $1.18(0.70$ to 2.03$)$ \\
\hline $55-64$ & $1.02(0.56$ to 1.84$)$ & $0.98(0.55$ to 1.79$)$ \\
\hline $65+$ & Referent & Referent \\
\hline \multicolumn{3}{|l|}{ Marital status } \\
\hline Never married & $1.87(1.25 \text { to } 2.80)^{* * *}$ & ${ }^{*} 1.47(0.96$ to 2.26$)$ \\
\hline $\begin{array}{l}\text { Divorced/separated/ } \\
\text { widowed }\end{array}$ & $0.86(0.61$ to 1.22$)$ & $0.94(0.66$ to 1.33$)$ \\
\hline Currently married & Referent & Referent \\
\hline
\end{tabular}

injury. In the marital group with the highest odds of injury (never married), residence was not associated with self reported injury. The association was strongest in the group with the lowest odds of injury (divorced/separated/widowed). It appears that in an already "at risk" group, rural residence is not a salient factor for self reported injury.

The pattern between self reported injury and marital status does not mirror what is known about the association between mortality and marital status. In general, studies have shown that divorced individuals have a higher risk of mortality compared with married groups, with never married individuals falling in between. ${ }^{20}$ In this study, while never married individuals had the greatest risk of self reported injury, no difference was seen between those who were currently married and those previously married (divorced/ separated/widowed). Yet, the fact of living in a rural county had the biggest impact on the previously married subgroup. While small numbers of actual injuries in these subpopulations prevented us from investigating differences in injury characteristics, further investigation along these lines would help to understand if the injuries themselves differed by these marital groups.

\section{NOMESCO coding}

To our knowledge this is the first time that the NOMESCO coding system was used for a telephone survey. This coding scheme provides a structure that is accessible because it does not require in-depth training on the coding of injuries and can be used in many different settings. In the survey by Nordstrom et al of respondents in a rural remote county, the activity at the time of the injury and how the injury happened were reported in narrative fashion. ${ }^{22}$ A trained medical records professional later coded these data. Their results were similar to results in this study. In the Iowa study $25 \%$ of injuries were due to overexertion and $21 \%$ from falls compared with $26 \%$ of injuries due to overexertion and close to $28 \%$ from falls in the Colorado rural population. Home was the most frequent place of injury in both studies: $26.6 \%$ in the Iowa study compared with $33.2 \%$ in rural respondents in the current study. Five percent of injuries occurred in recreation 


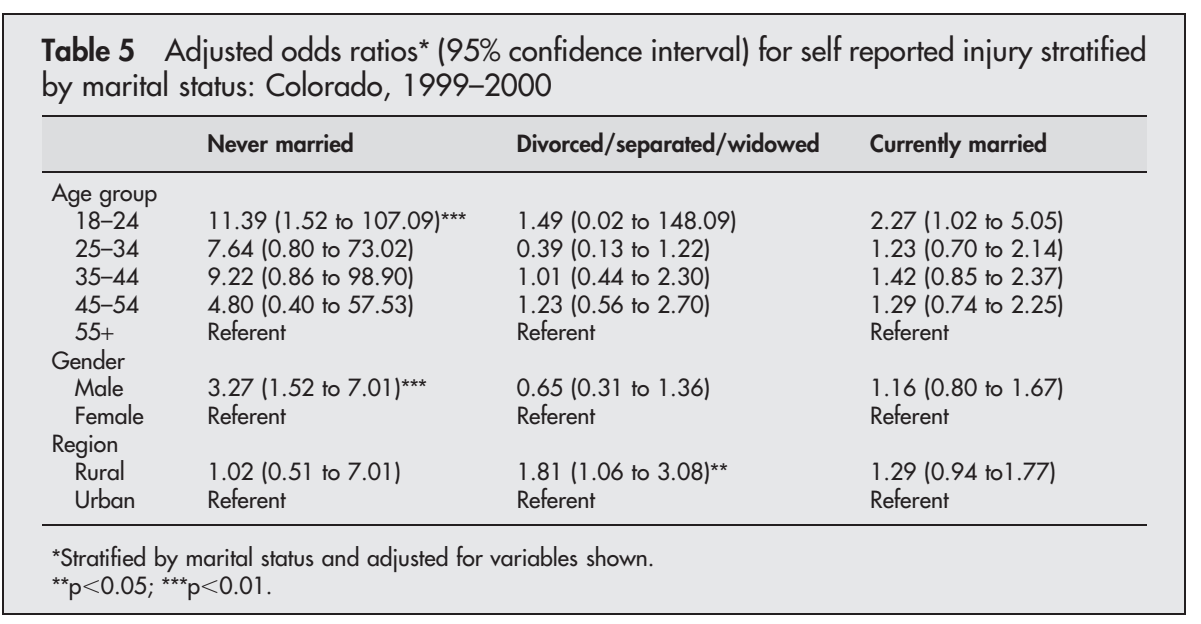

and sport facilities compared with $9.5 \%$ of injuries to rural residents in this study.

\section{Study limitations}

Recall of injuries within the last 12 months yields the lowest injury incidence rate when compared with other shorter recall intervals. ${ }^{23-25}$ Using a 12 month recall results in an underestimation of injury occurrences. Yet, when using shorter recall periods, larger sample sizes are needed to acquire enough injuries in the data to be able to describe differences in injury characteristics among subpopulations. Since the sample size was limited and the goal of this survey was to assess differences not only the proportion of urban and rural adults experiencing injury but also differences in injury characteristics between these two populations, a 12 month recall period was used.

While the proportion of those experiencing an injury in the last 12 months is probably underestimated by using the 12 month recall, the magnitude of the difference found in nonfatal injury between urban and rural residents would only be biased if urban or rural residents were more or less likely to report injuries in this time period. One variable not studied that could possibly influence differences in recall between these two groups is access and use of health care. One such measure of access is health insurance coverage. A larger proportion of rural than urban residents are known to be uninsured. ${ }^{26-28}$ Would having sought medical care for an injury for which others with less access to care would not have sought such care result in more accurate recall among urban residents? Harel et al in their study of recall of childhood injuries found that doctor visits due to injuries could not explain the variation in recall for the various time periods. ${ }^{25}$ More work is needed to understand how access to care and use of health services for injuries in adults influence recall in reporting injury.

One variable known to influence recall is severity of injury with severe injuries showing less recall bias than minor injuries. ${ }^{23-25}$ Using number of days of missed regular activity as an estimate of severity, the distribution of this variable was similar for rural and urban residents (table 3 ). This would support the idea that recall bias did not act selectively for one group over the other. Thus, while the true estimate of injury is probably more than stated in this paper, one would not expect that the magnitude of the differences between urban and rural residents found were biased by using a 12 month recall.

Due to funding constraints, the time frame for collection of data differed between the urban and rural groups, with collection continuing for nine months more in the rural

\section{Key points}

- Data suggest that when adjusted for age, gender, and marital status, rural residents are more likely to experience non-fatal injury than urban residents.

- Yet, rural residence was not found to be a risk factor for injury among the never married population, but was among the divorced/separated/widowed population.

- No major differences were seen in the injury characteristics reported by rural and urban residents.

- NOMESCO coding is a viable alternative for coding of injuries for telephone surveys.

group than in the urban group. We found no differences within the rural respondents in regard to demographic characteristics and reported injury by year of interview or by month of interview. The results assessing significant risk factors for injury were similar when limiting the analysis to data only collected in 1999. In addition, the estimates of injury to rural remote residents are comparable to those reported in a population based survey of a rural remote Iowa county. ${ }^{22}$ Thus, we believe that the difference in time frame did not affect comparisons between rural and urban residents.

More than $99 \%$ of the injuries reported were unintentional. Estimates from the Consumer Product Safety Commission's National Electronic Injury Surveillance System estimated that $6.4 \%$ of all injuries seen in emergency departments in 2000 were for violence related, intentional injuries. ${ }^{29}$ In previous population based telephone surveys, data have been gathered on domestic violence and other types of intentional injury. ${ }^{30-33}$ The other surveys had specific questions about specific types of intentional injuries. Our findings suggest that direct questions about intentional injuries should be included as specific, separate questions, as those reported here probably represent an under-estimate of intentional injuries.

Despite the study limitations, the results reported are consistent with other surveys. The results also provide evidence that rural residence is an independent risk factor for non-fatal injury but not for persons who have never been married. In that group, other risk factors such as being male and young age are more salient risk factors. While the risk of injury appears higher in some segments of rural populations, 
no differences were seen in the cause of injury, place of injury, and activity at the time of injury between urban and rural residents. More research is needed to understand the moderating effect of marital status on such injury risk factors as rural residence, age, and gender.

\section{ACKNOWLEDGEMENTS}

This publication was supported in part by Grant Number R49/ CCR811509 from the Centers for Disease Control and Prevention. Its contents are solely the responsibility of the authors and do not necessarily represent the official views of the Centers for Disease Control and Prevention.

We wish to thank Darci Cherry and David Brand, former research associates with the Survey Research Unit at the Colorado Department of Public Health and Environment (CDPHE), as well as the interviewing staff of the Survey Research Unit for their work on this project. In addition, we would like to thank Katy Meng of the Injury Epidemiology Program (CDPHE) for information on injury mortality rates for urban and rural counties in Colorado.

\section{Authors' affiliations}

M Leff, Department of Environmental and Radiological Health Sciences and Colorado Injury Control Research Center, Colorado State University, Ft Collins

L Stallones, Department of Psychology and Colorado Injury Control Research Center, Colorado State University, Ft Collins

T J Keefe, Department of Environmental and Radiological Health Sciences, Colorado State University, Ft Collins

R Rosenblatt, M Reeds, Colorado Department of Public Health and Environment, Denver

\section{REFERENCES}

1 Anderson RN. Deaths: leading causes for 2000. Natl Vital Stat Rep 2002;50:1-85.

2 Baker SP, O'Neill B, Ginsburg MJ, et al. The injury fact book. 2nd Ed. New York: Oxford University Press, 1992:52-5.

3 Stella J, Sprivulis P, Cooke C. Head injury-related road crash mortality in rural Western Australia. Aust N Z J Surg 2001;71:665-8

4 Hwang HC, Stallones L, Keefe TJ. Childhood injury deaths: rural and urban differences, Colorado 1980-8. Inj Prev 1997;3:35-7.

5 Gabella BA, Hoffman RE, Marine WW, et al. Urban and rural traumatic brain injuries in Colorado. Ann Epidemiol 1997;7:207-12.

6 Hambidge SJ, Davidson AJ, Gonzales R, et al. Epidemiology of pediatric injury-related primary care office visits in the United States. Pediatrics 2002; 109:559-65.

7 Reith DM, Pitt WR, Hockey R. Childhood poisoning in Queensland: an analysis of presentation and admission rates. J Paediatr Child Health 2001;37:446-50.

8 Centers for Disease Control and Prevention. Behavioral Risk Factor Surveillance System Surveillance guide. Atlanta, GA: CDC. Available at http://ww2.cdc.gov/nccdphp/brfss2/training laccessed on 20 August 2002).

9 NOMESCO Working Group for Classification for Accident Monitoring NOMESCO classification of external causes of injuries. 3rd Revised editions. Copenhagen: NOMESCO, 1997:28-48

10 Frimodt-Moller B, Bay-Nielsen H. Classification of accidents in the arctic. A suggestion for adaptation of the Nordic classification for accident monitoring. Arct Med Res 1992;51(suppl):15-21.
11 Centers for Disease Control and Prevention. Behavioral Risk Factor Surveillance System questionnaire. Atlanta, GA: US Department of Health and Human Services, CDC, 1999.

12 US Department of Health and Human Services. The 2000 HHS poverty guidelines. Washington, DC: US Department of Health and Human Services, Available on: http://aspe.hhs.gov/poverty/00poverty.htm (accessed on 7 January 2002).

13 Centers for Disease Control and Prevention. Behavioral Risk Factor Surveillance System. Atlanta, GA: CDC, Available at: http://www.cdc.gov/ brfss/ti-weighting.htm (accessed on 15 August 2001).

14 SAS Institute Inc. SAS guide for personal computers, version 8.1. Cary, NC: SAS Institute Inc, 2000.

15 Raghunathan TE, Solenberger PW, VanHoew J. IVEware: imputation and variance estimation software. Survey Methodology Program, Survey Research Center, Institute for Social Research, University of Michigan. Available at: http://www.isr.umich.edu/src/smp/ive (accessed on 15 July 2002).

16 Lemeshow S, Hosmer DW. Applied logistic regression. New York: Wiley, 2000:211-21.

17 Centers for Disease Control and Prevention. Behavioral Risk Factor Surveillance System. Atlanta, GA: CDC, Available at: http://www.cdc.gov/ brfss/ti-quality.htm (accessed on 20 August 2002).

18 Colorado Department of Public Health and Environment. Injury in Colorado. Denver, CO: Colorado Department of Public Health and Environment, 2002;139:40-1.

19 Colorado Department of Public Health and Environment. Colorado health information data set. Denver, CO: Colorado Department of Public Health and Environment. Available at: http://www.cdphe.state.co.us/cohid/Cohids.html (accessed on 15 October 2002).

20 Singh GK, Siahpush M. Ethnic-immigrant differentials in health behaviors, morbidity, and cause-specific mortality in the United States: an analysis of two national databases. Hum Biol 2002;74:83-109

21 Tucker JS, Friedman HS, Wingard DL, et al. Marital history at midlife as a predictor of longevity: alternative explanation to the protective effect of marriage. Health Psychol 1996;36:230-43.

22 Nordstrom DL, Zwerling C, Stromquist AM, et al. Epidemiology of unintentional adult injury in a rural population. J Trauma 2001;51:758-66.

23 Mock C, Acheampong F, Adjei S, et al. The effect of recall on estimation of incident rates for injury in Ghana. Int J Epidemiol 1999;28:750-5.

24 Landen DD, Hendricks S. Effect of recall on reporting of at-work injuries. Public Health Rep 1995; 1 10:350-4.

25 Harel Y, Overpeck MD, Jones DH, et al. The effects of recall on estimating annual nonfatal injury rates for children and adolescents. Am J Public Health 1994;84:599-605

26 Frenzen PD. Health insurance coverage in the US urban and rural areas. J Rural Health 1993:9:204-14.

27 Hartley D, Quam L, Lurie N. Urban and rural differences in health insurance and access to care. J Rural Health 1994;10:98-108.

28 Duncan RP, Seccombe K, Amey C. Changes in health insurance coverage within rural and urban environments -1977 to 1987 . J Rural Health 1995; 11:169-76.

29 Office of Statistics and Programming, National Center for Injury Prevention and Control, Centers for Disease Control and Prevention. National estimates of nonfatal injuries treated in hospital emergency departments - United States, 2000. MMWR Morb Mortal Wkly Rep 2001;50:340-1.

30 Buehler J, Dixon B, Toomey K. Lifetime and annual incidence of intimate partner violence and resulting injuries, Georgia, 1995. MMWR Morb Mortal Wkly Rep 1998:47:849-53.

31 Bensley L, Macdonald S, Van Eenwyk J, et al. Prevalence of intimate partner violence and injury-Washington, 1998. MMWR Morb Mortal Wkly Rep 2000;49:589-92

32 Coker AL, Odendick R, Derrick J. Intimate partner violence among men and women-South Carolina, 1998. MMWR Morb Mortal Wkly Rep 2000;49:691-4.

33 Koziol-McLain J, Brand D, Morgan D, et al. Measuring injury risk factors: question reliability in a statewide sample. Inj Prev 2000;6:148-50. 